\title{
A simple model for the short-time evolution of near-surface current and temperature profiles
}

\author{
Alastair D. Jenkins ${ }^{\mathrm{a}, *}$, Brian Ward $^{\mathrm{b}}$ \\ ${ }^{a}$ Bjerknes Centre for Climate Research, Geophysical Institute, Allégaten 70, 5007 \\ Bergen, Norway \\ ${ }^{\mathrm{b}}$ Woods Hole Oceanographic Institution, Woods Hole, Massachusetts, U.S.A.
}

\begin{abstract}
A simple analytical/numerical model has been developed for computing the evolution, over periods of up to a few hours, of the current and temperature profile in the upper layer of the ocean. The model is based upon conservation laws for heat and momentum, and employs an eddy diffusion parameterisation which is dependent on both the wind speed and the wind stress applied at the sea surface. Other parameters such as the bulk-skin surface temperature difference and $\mathrm{CO}_{2}$ flux are determined by application of the Molecular Oceanic Boundary Layer Model (MOBLAM) of Schlüssel and Soloviev. A similar model, for the current profile only, predicts a temporary increase in wave breaking intensity and decrease in wave height under conditions where the wind speed increases suddenly, such as, for example, during gusts and squalls. The model results are compared with measurements from the lagrangian Skin Depth Experimental Profiler (SkinDeEP) surface profiling instrument made during the 1999 MOCE-5 field experiment in the waters around Baja California. SkinDeEP made repeated profiles of temperature within the upper few metres of the water column. Given that no tuning was performed in the model, and that the model does not take account of stratification, the results of the model runs are in rather good agreement with the observations. The model may be suitable as an interface between time-independent models of processes very near the surface, and larger-scale three-dimensional time-dependent ocean circulation models. A straightforward extension of the model should also be suitable for making time-dependent computations of gas concentration in the near-surface layer of the ocean.
\end{abstract}

Key words: Temperature, current, turbulence, sea surface, mathematical modelling, profiling instrument

* Corresponding author. Tel.: +47-55 58 2632; fax: +47-55 589883.

Email address: alastair.jenkins@bjerknes.uib.no (Alastair D. Jenkins).

URL: http://www.gfi.uib.no/ jenkins (Alastair D. Jenkins). 


\section{Introduction}

The temperature of the sea surface, and its relation to that of the adjacent atmosphere and water column, are vitally important parameters for the air-sea exchange of heat (Fairall et al. 1996a) and gas species (McNeil and Merlivat 1996; Fairall et al. 2000; Ward et al. 2004a). For global estimation of atmosphere-ocean heat and gas flux, it is necessary to relate satellite observations of radiative surface skin temperature $T_{S}$ to the bulk temperature $T_{B}$ of the upper centimetre or so of the water column (Schlüssel et al. 1990; Donlon et al. 2002). This bulk-skin temperature difference $\Delta T_{B-S}=T_{B}-T_{S}$ is a function of the ambient radiative, mechanical, and thermal forcing, and is generally positive and equal to a few tenths of a degree, primarily as a result of the cooling of the water by outgoing long-wave radiation emitted in a thin layer of the order of $1 \mu \mathrm{m}$ deep. The transition zone from this skin layer to the bulk is controlled primarily by molecular heat conduction and has a thickness of the order of $1 \mathrm{~mm}$.

A number of different theoretical and numerical models exist for the calculation of $\Delta T_{B-S}$ (Eifler 1992, 1993; Jessup et al. 1995; Soloviev and Schlüssel 1994). These models can be quite complex, since they compute many interrelated parameters, and, since they consider processes with a small time scale, are generally in time-independent form. Alternatively, one can use such techniques as neural network methods to derive empirically the relation between the forcing parameters and $\Delta T_{B-S}$ (Ward and Redfern 1999).

In the upper 10-50 m layer of the water column, time-dependent three-dimensional ocean circulation models may employ simple algebraic parameterisations for turbulent fluxes of momentum, heat, and mass. They may also use some form of turbulence closure technique (e.g. Burchard et al. 1998), albeit at greater computational expense. Even more expensive computationally are direct numerical simulations of vortex structures (e.g. Nagaosa 1999).

In this paper we employ a time-dependent model which should be applicable to the zone intermediate between the surface millimetre layer where the skin effect occurs and the $\approx 10 \mathrm{~m}$ level which can be resolved by oceanic circulation models. The model is thus useful in describing or parameterising the coupling between the different model scales. It uses a simple parameterisation of turbulent flux processes, so that it should be numerically stable and com-

putationally inexpensive. The model codes and documentation are specified in Jenkins and Ward (2003).

We compare results of the model with near-surface temperature profiles obtained using the Skin Depth Experimental Profiler (SkinDeEP, Ward et al. $2004 \mathrm{~b})$. It is an autonomous profiler, carrying high-resolution temperature 
sensors to provide a record of the bulk temperature. It was deployed during the Marine Optical Characterisation Experiment (MOCE-5), cruise in the Gulf of California during the period 1999 October 1-21 (Ward and Minnett 2004).

\section{Model formulation and specification}

\subsection{Physical basis of the model}

The flux of momentum, heat, and mass between the atmosphere and the ocean is to a large extent controlled by turbulence in the atmospheric and oceanic boundary layers, although stratification (Monin and Obukhov 1954), the Earth's rotation (Ekman 1905), surface waves (Janssen 1989; Jenkins 1987a, 1989; Weber 1983), the presence of laminar layers close to the surface, and the short-wave and long-wave radiation balance (Schlüssel et al. 1990) can also be important. The effect of turbulence may be modelled by eddy viscosity (Madsen 1977) or turbulence closure models which have reached a great degree of complexity and sophistication (e.g. Burchard et al. 1998). However, one difficulty that may arise when applying turbulence closure models in calculating properties very close to the sea surface is the choice of boundary condition: in general, it may be necessary to specify a roughness length in a more-or-less arbitrary fashion, and the values of mean velocity, temperature, and concentration near the water surface may have a behaviour which is close to singular and thus difficult to resolve numerically. The partial differential equations which are obtained from a turbulence closure formulation may be rather complex and their solutions may pose analytical and/or numerical difficulties.

The model approach employed in this paper is designed to avoid some of the difficulties described above, by combining physical conservation laws with some general properties of turbulent boundary layers and empirical observations. The physical conservation laws are those of momentum, heat, and mass: the rate of change of the momentum of the water column is given by the applied wind stress; likewise the atmosphere-ocean heat flux is given by (or determines) the rate of change of the total heat content of the water column, and the flux of a substance through the sea surface determines the rate of change of its concentration in the water column. The empirical observations are as follows: the mean velocity (current) at the sea surface is determined, not by a relationship between the applied wind stress and the vertical velocity gradient, mediated by a viscosity or turbulent eddy viscosity, but, instead, as a fraction $\lambda \approx 0.02$ of the wind speed $U$. Thus, the value of the wind-induced surface current has a relatively stable behaviour, which is in agreement with 
the practical engineering calculations made in connection with observations of the drift of floating objects and of oil slicks, and the measurement of nearsurface currents using moored current meters and surface drifters (Audunson 1979; Huang 1979, 1983; Jenkins 1987a,b). Although the physical reason for this behaviour of the surface current may not be strictly evident, we may consider that an increasing wind stress will cause an increasing vertical velocity shear, but it will also cause an increase in turbulent motion which will transport momentum more rapidly downwards, thus decreasing the shear. The corresponding conditions for temperature and concentration would be equal temperatures and concentrations just above and below the water surface, although corrections need to be applied for the presence of a laminar boundary layer and the thermal radiation balance (Schlüssel et al. 1990).

The effect of turbulence in transporting momentum, heat, and mass vertically can be parameterised in terms of a mixing length proportional to the distance from the surface, as in the usual turbulent boundary-layer of Prandtl and von Kármán. However, we show that if we assume a simple functional form (Eq. 1 below) for the time-dependent behaviour of the current, temperature, etc., combined with the conservation laws for momentum, heat, and mass, and the empirical surface boundary conditions discussed above, an effective 'mixing length' scale appears as a consequence. Although the physical boundary conditions at the sea surface and at the sea bottom are fundamentally different, there is evidence from observations of wind-induced surface currents (Huang 1979, 1983; Jenkins 1984; Jenkins et al. 1986), temperature (Soetje and Huber 1980; Burchard 2002, section 7.3.2), and the behaviour of air bubbles in the water column (Thorpe 1984), that a substantial vertical velocity shear can exist near the surface, consistent with an increase in effective eddy viscosity with increasing distance from the surface, as in Madsen's 1977 approach.

\subsection{Predicted current profile}

For an ocean initially at rest, we consider at first the following evolution of the current $u(z, t)$ at time $t$ and depth $-z$ :

$$
u(z, t)=\lambda U \exp \left[\lambda U z /\left(u_{*}^{2} t\right)\right]
$$

where $u_{*}$ is the friction velocity within the water column, $\tau=\rho_{w} u_{*}{ }^{2}=\rho_{a} U_{*}{ }^{2}$ being the wind stress. $U_{*}, \rho_{a}$, and $\rho_{w}$ are the friction velocity in the atmosphere, the air density and the water density respectively. Equation 1 satisfies the 
conservation of momentum:

$$
\rho_{w} \frac{d}{d t} \int_{-\infty}^{0} u(z, t) d z=\rho_{a} U_{*}^{2}
$$

where for simplicity we neglect the Coriolis force.

The current $u(z, t)$ in (1) obeys the equation

$$
\frac{\partial u}{\partial t}=-\frac{u_{*}^{2} z}{\lambda U} \frac{\partial^{2} u}{\partial z^{2}}
$$

with $-u_{*}^{2} z /(\lambda U)$ playing a role similar to that of an eddy viscosity, as in turbulent boundary layer flow near a rigid wall. We may also consider this 'quasi eddy viscosity' to be a product of a turbulent velocity scale equal to $u_{*}$ and an effective turbulent roughness length equal to $-u_{*} z /(\lambda U)$.

If the wind speed is allowed to vary with time we can alter (1) so that it becomes

$$
u(z, t)=\int_{0}^{t} \lambda \frac{d U\left(t^{\prime}\right)}{d t^{\prime}} \exp \left[\frac{\lambda U\left(t^{\prime}\right) z}{\left(u_{*}\left(t^{\prime}\right)\right)^{2}\left(t-t^{\prime}\right)}\right] d t^{\prime} .
$$

In this case, the partial differential equation (3) does not hold, as the system retains a 'memory' of the wind forcing at previous points in time. The memory is effectively longer at large depths than near the surface.

Figure 1, from Jenkins (2001), shows the model predictions for the current induced by a wind of $20 \mathrm{~m} / \mathrm{s}$ blowing for 2 hours followed by an increased wind of $30 \mathrm{~m} / \mathrm{s}$. The current profiles are calculated every 5 minutes. We assume that $\lambda=0.02$, and $u_{*}=\left(C_{D} \rho_{a} / \rho_{w}\right)^{1 / 2} U$, with $\rho_{a} / \rho_{w}=1 / 800, C_{D}=A+B U$, $A=0.8 \times 10^{-3}$, and $B=0.065 \times 10^{-3} \mathrm{~m}^{-1} \mathrm{~s}(\mathrm{Wu} 1982)$.

Effect of the modelled current on surface waves

Wave spectra have been calculated by using the Donelan et al. (1985) formulation for limited fetch, transformed by means of the wave group velocity to apply to winds blowing for limited times. Calculations have also been made of the effect of the computed vertical current shear on the wave height required for wave breaking, according to the theory of Banner and Phillips (1974). Results of these calculations (Figure 2) indicate that a rapid increase in wind speed will tend to increase the intensity of wave breaking so that the wave height will decrease by a small factor, of order $6 \%$ according to linear wave 


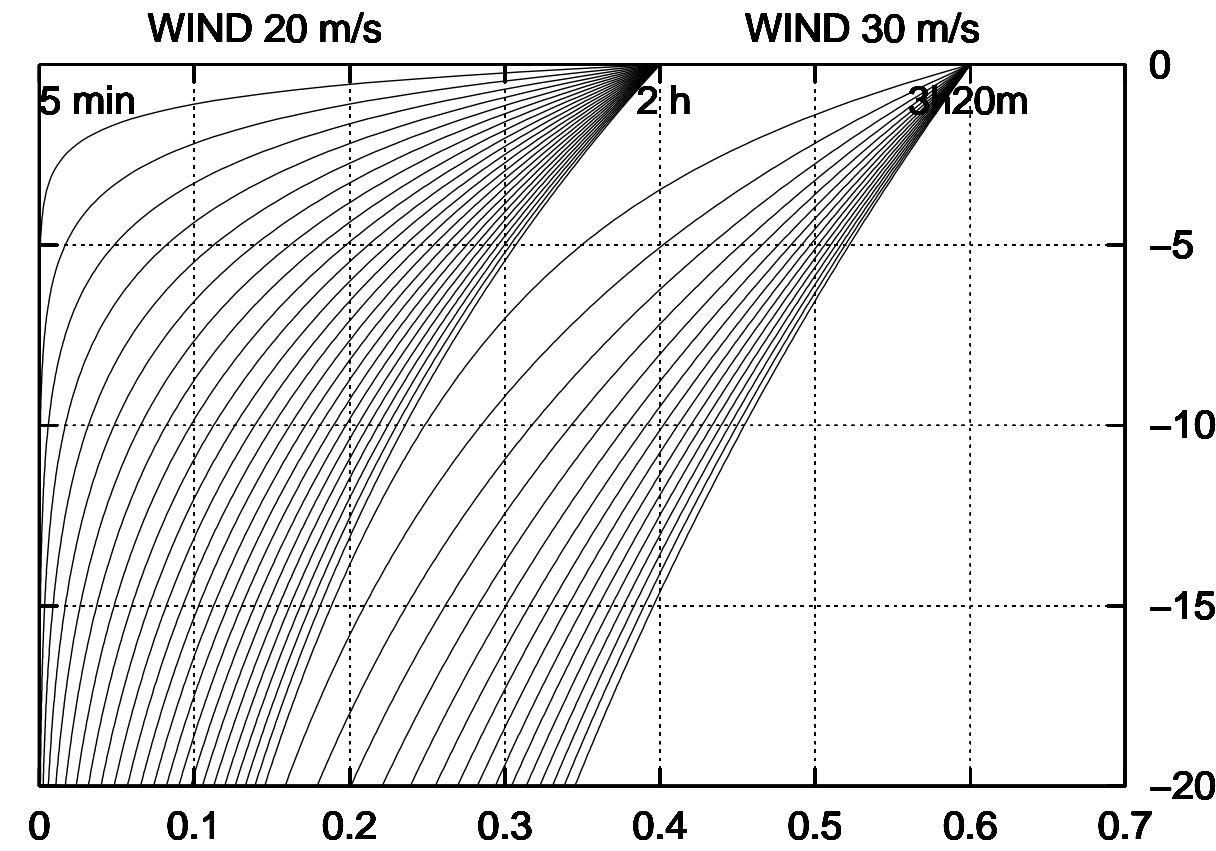

$\mathrm{u} / \mathrm{m} \mathrm{s}^{\wedge}-1$

Fig. 1. Example of the evolution of a current profile using the present model. (From Jenkins 2001). (C) 2001, ASCE. Reproduced by permission of the publisher, ASCE. http://www.pubs.asce.org

theory, but this factor may be as much as $25 \%$ according to time-dependent nonlinear numerical simulations by Banner et al. (2000).

\subsection{Heat flux}

If we now consider the diffusion of heat within the water column, we obtain a corresponding formula for the evolution of the temperature $T$ :

$$
T(z, t)=T_{0}+\int_{0}^{t} \frac{d T\left(0^{-}, t^{\prime}\right)}{d t^{\prime}} \exp \left[\frac{\lambda U\left(t^{\prime}\right) z}{\left(u_{*}\left(t^{\prime}\right)\right)^{2}\left(t-t^{\prime}\right)}\right] d t^{\prime}
$$

where $T_{0}$ is the initial temperature, and $T\left(0^{-}, t\right)$ is the bulk temperature just below the surface skin layer. Here we assume that turbulence diffuses heat at the same rate as it diffuses momentum. We may adjust the relative values of the turbulent diffusion coefficients for heat and momentum by altering the value of the parameter $\lambda$. The model is assumed to be horizontally homogeneous, and the effect of density stratification on the turbulent diffusion of heat 

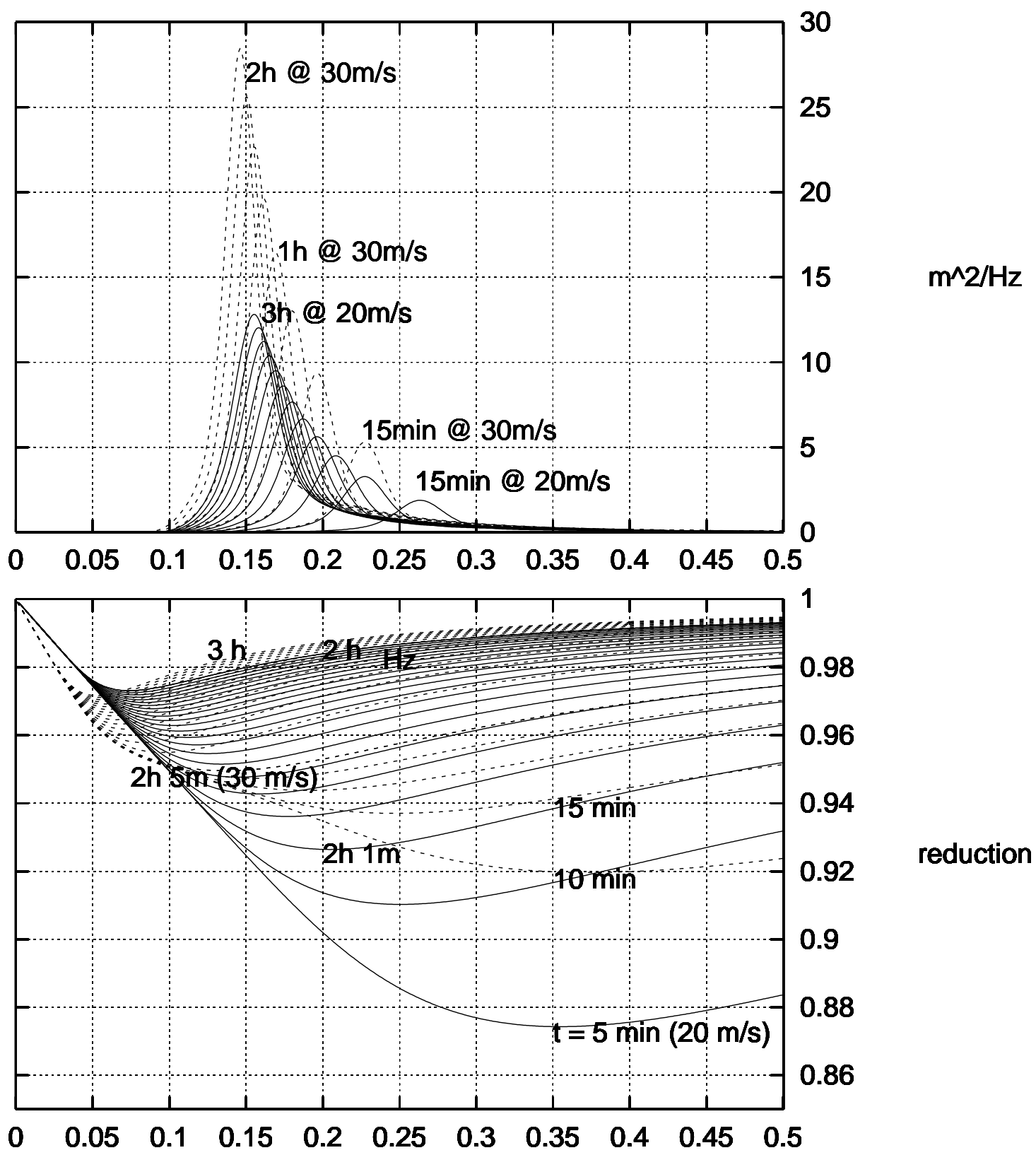

$\mathrm{Hz}$

Fig. 2. Wave spectra from the Donelan/Hamilton/Hui model, and computed reduction in amplitude of maximum non-breaking waves. (From Jenkins 2001). (c) 2001, ASCE. Reproduced by permission of the publisher, ASCE. http://www.pubs. asce.org.

is neglected. 


\subsection{Characteristic behaviour of the model}

It may be considered that the model presented in this paper produces results which are at variance with the turbulence closure and eddy diffusion models normally employed. In particular, the evolution of the current, temperature, or concentration of a tracer, driven by a step-function forcing of wind stress, surface temperature, etc., produces results which imply that the eddy viscosity or diffusivity increases with time and tends to an infinite value for infinite time. However, this behaviour does not make the model invalid. We are here assuming infinite depth and neglecting the influence of stratification and rotation, and in such a case there is no natural limit to the size of turbulent eddies which may be produced. Such eddies may grow indefinitely, and the effective eddy viscosity or diffusivity has a term which increases linearly with time. If the eddy viscosity may be regarded as proportional to the product of a velocity scale $\left(u_{*}\right)$ and a length scale (the size of turbulent eddies), this will mean that such eddies should increase in size linearly with time, consistent with the lack of a natural limit to eddy size. For a constant wind speed $U$ and surface bulk temperature $T\left(0^{-}\right)$, a steady state would have a constant current $\lambda U$ and a depth-independent temperature $T\left(0^{-}\right)$. However, this steady state will be reached very slowly in the assumed case of infinite water depth and zero Coriolis force.

In addition, it is by no means assured that the vertical transport may be parameterised by means of an eddy viscosity or diffusivity. The model may be criticised for the fact that the velocity, temperature, or concentration gradient decreases to zero with increasing time: however, it is well known that it is not uncommon in turbulent flows for counter-gradient transport to occur, so that a finite flux of momentum/heat/mass under zero-gradient conditions should not be an unusual effect. It is common in the modelling of atmospheric turbulent diffusion for non-local transport algorithms to be used (e.g. Stull 1993), and such algorithms almost invariably lead to counter-gradient transport in at least part of the domain, in agreement with results using large-eddy simulation algorithms (Skyllingstad and Denbo 1995).

It is in fact possible to re-write Eq. 3 as an advection-diffusion equation, ${ }^{1}$

$$
\frac{\partial u}{\partial t}+w \frac{\partial u}{\partial z}-\frac{\partial}{\partial z}\left(\nu_{E} \frac{\partial u}{\partial z}\right)=0
$$

employing the same value for eddy viscosity, $\nu_{E}=-u_{*}^{2} z /(\lambda U)$, as mentioned previously. The turbulent flux of momentum is thus expressed here as the sum of a downgradient and a no-gradient flux. The no-gradient flux is described

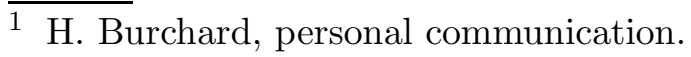


Table 1

SkinDeEP deployment information for the measurements presented in this paper

\begin{tabular}{|c|r|l|l|l|l|}
\hline Date & $\begin{array}{r}\text { Stat. } \\
\text { no. }\end{array}$ & \multicolumn{1}{c|}{$\begin{array}{c}\text { Station } \\
\text { name }\end{array}$} & $\begin{array}{c}\text { Times } \\
\text { LST }\end{array}$ & $\begin{array}{c}\text { No. of } \\
\text { profiles }\end{array}$ & \\
\hline $1999-10-04$ & 4 & Punta Magdalena & $10: 59-13: 24$ & 120 & $25^{\circ} 09.49^{\prime} \mathrm{N}, 112^{\circ} 59.52^{\prime} \mathrm{W}$ \\
$1999-10-10$ & 10 & T/S Irwin & $11: 12-14: 13$ & 161 & $22^{\circ} 31.48^{\prime} \mathrm{N}, 109^{\circ} 35.43^{\prime} \mathrm{W}$ \\
$1999-10-14$ & 14 & Isla San Esteban 2 & $06: 15-07: 44$ & 78 & $28^{\circ} 36.15^{\prime} \mathrm{N}, 112^{\circ} 32.04^{\prime} \mathrm{W}$ \\
\hline
\end{tabular}

by a downward vertical advection velocity $w=-u_{*}^{2} /(\lambda U)$. Note that this advection velocity is in general much smaller than $u_{*}$, so in our opinion it should not be regarded as unphysical.

The eddy viscosity may still be described as the product of a velocity scale $u_{*}$ and a turbulent length scale $-u_{*} z /(\lambda U)=-\lambda^{-1}\left(C_{D} \rho_{a} / \rho_{w}\right)^{1 / 2} z$. If we let the eddy viscosity profile be described in terms of a von Kármán 'constant' $\kappa$, i.e. $\nu_{E}=-\kappa u_{*} z$, we have $\kappa=u_{*} /(\lambda U)=\lambda^{-1}\left(C_{D} \rho_{a} / \rho_{w}\right)^{1 / 2}$. This value of $\kappa$ is generally smaller than the 'classical' value of $\approx 0.4$ : for the parameter values used here (see section 2.2), $\kappa$ increases with wind speed, being 0.050 at $U=0 \mathrm{~m} / \mathrm{s}$ and 0.081 at $U=20 \mathrm{~m} / \mathrm{s}$.

\section{Measurements}

A detailed description of the SkinDeEP instrument, which uses an FP07 thermistor and a high-resolution platinum wire $(\mathrm{Pt})$ temperature sensor, is given by Ward and Minnett (2002) and Ward et al. (2004b). The instrument is able to rise and sink autonomously, changing its density by inflating and deflating an external neoprene sleeve, and measurements are made during its ascending phase only.

The instrument was deployed during the MOCE-5 cruise, in the waters around Baja California (Ward and Minnett 2004). Data were acquired from ten stations: Table 1 summarises the deployment information for the three stations where the results are shown in this report. The measurements reported here are from the FP07 thermistor, as data from the Pt sensor were not available for this cruise.

Other observations made include the following:

- Sea-surface skin temperature by the M-AERI passive infrared radiometric interferometer, using the $500-3000 \mathrm{~cm}^{-1}$ wavelength range, which has an accuracy of better than $0.05^{\circ}$ (Minnett et al. 2001; Minnett and Ward 2000); 
- Bulk water temperature measurements from the ship intake and from a floating sensor (an inverted hard plastic helmet filled with foam with a thermistor just below the waterline);

- Air temperature, wind speed, and net heat flux.

All three measurement series presented here are for periods with rather light winds, between 0.7 and $4.5 \mathrm{~m} \mathrm{~s}^{-1}$. The air temperature is less than the sea surface temperature (measured by SkinDeEP) on October 4, is greater than the surface temperature on October 14, and on October 10 the air and sea surface temperatures are quite similar. The net heat flux is positive (from air to sea) in all three cases. The net heat flux is primarily incident short-wave radiation, and is mostly absorbed in the upper $0.1 \mathrm{~m}$ of the water column (Schlüssel et al. 1990).

Shipboard logistics dictated that SkinDeEP was deployed during the afternoon to facilitate other operations, which is the timeframe when measurements were made on October 4 and 10. An exception to this routine was made on one day (October 14), when the profiler was deployed early in the morning. As measurements began shortly before sunrise, this was the only nighttime dataset, and was too limited to provide any conclusive evidence for daytimenighttime differences.

\section{Model results}

Figures 3-5 show SkinDeEP measurements from three of the MOCE-5 stations, together with background atmospheric parameters and net heat flux. Results of model simulations from equation 5 are shown at the bottom of each figure. The model is started with a uniform temperature at the time corresponding to the left-hand side of the plot, and the surface boundary condition $T\left(0^{-}, t\right)$ is set equal to the uppermost water temperature measured by the SkinDeEP profiler (at a depth of approximately $0.5 \mathrm{~cm}$, in the bulk, below the surface skin layer). The value $u_{*}=\left(C_{D} \rho_{a} / \rho_{w}\right)^{1 / 2} U$ in (5) is computed using the drag coefficient formula of $\mathrm{Wu}(1982): C_{D}=A+B U, A=0.8 \times 10^{-3}$, and $B=0.065 \times 10^{-3} \mathrm{~m}^{-1} \mathrm{~s}$.

The ocean is assumed to be horizontally homogeneous, and neither the effect of stratification nor of the Coriolis force are taken into account. The current and waves were not calculated in this case, since no observations of current or waves were available.

1999 October 4:

In this situation the air temperature is lower than the sea temperature, but 


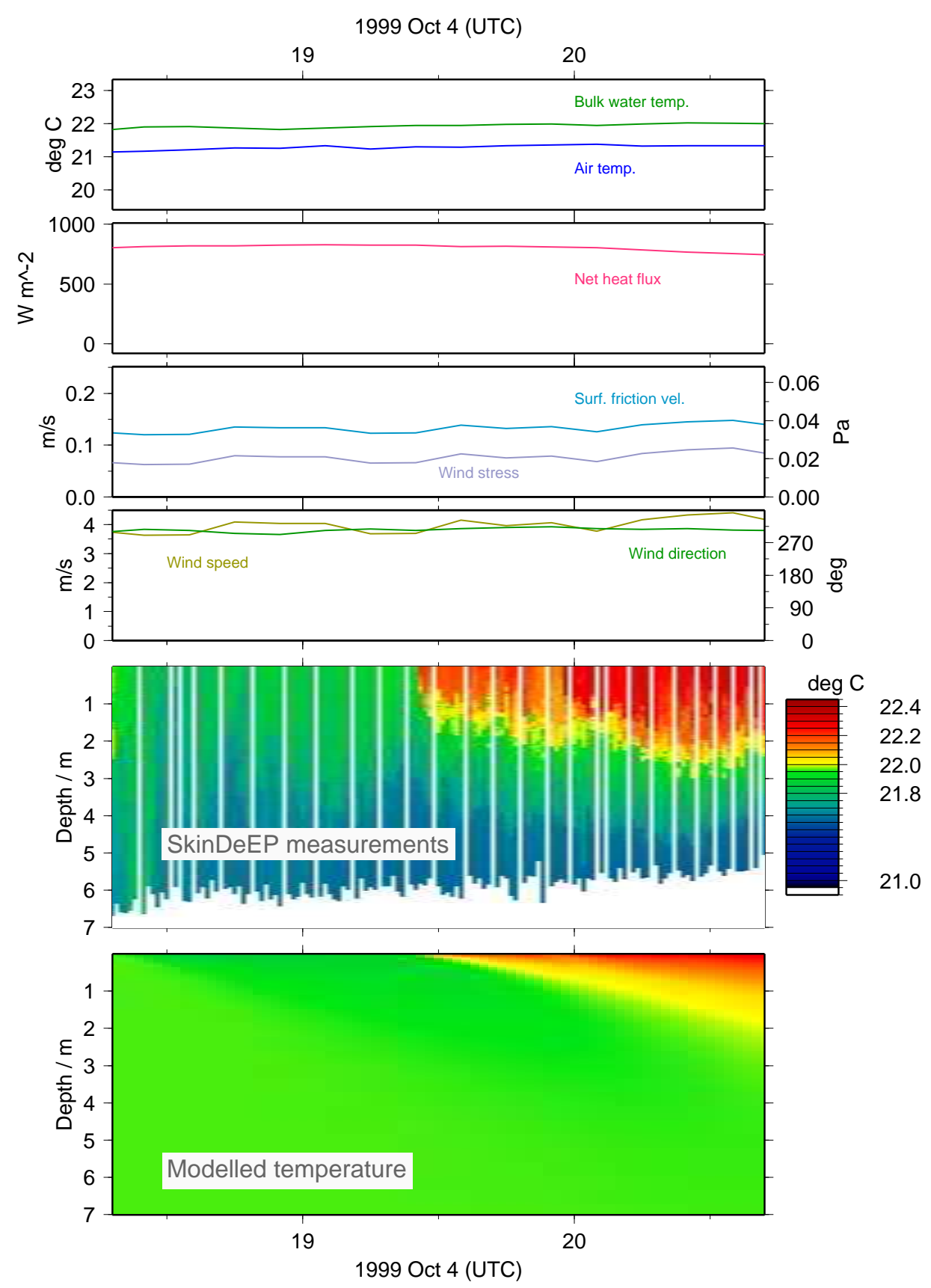

Fig. 3. Observations and model results from Station Punta Magdalena, 1999 October 4 .

the net positive heat flux should tend to increase the bulk temperature near the sea surface. The observed warming of the surface layer at around 12:30 is likely to be due to horizontal advection. Nevertheless, the model does predict an increase in depth of the warm surface layer $\left(T>22^{\circ} \mathrm{C}\right)$ to $2 \mathrm{~m}$ by the end of the observation period, which is of the same order as the depth increase which is actually observed. It may also be the case that the model parameterization, which predicts a 'von Kármán coefficient' lower than the classical value of 

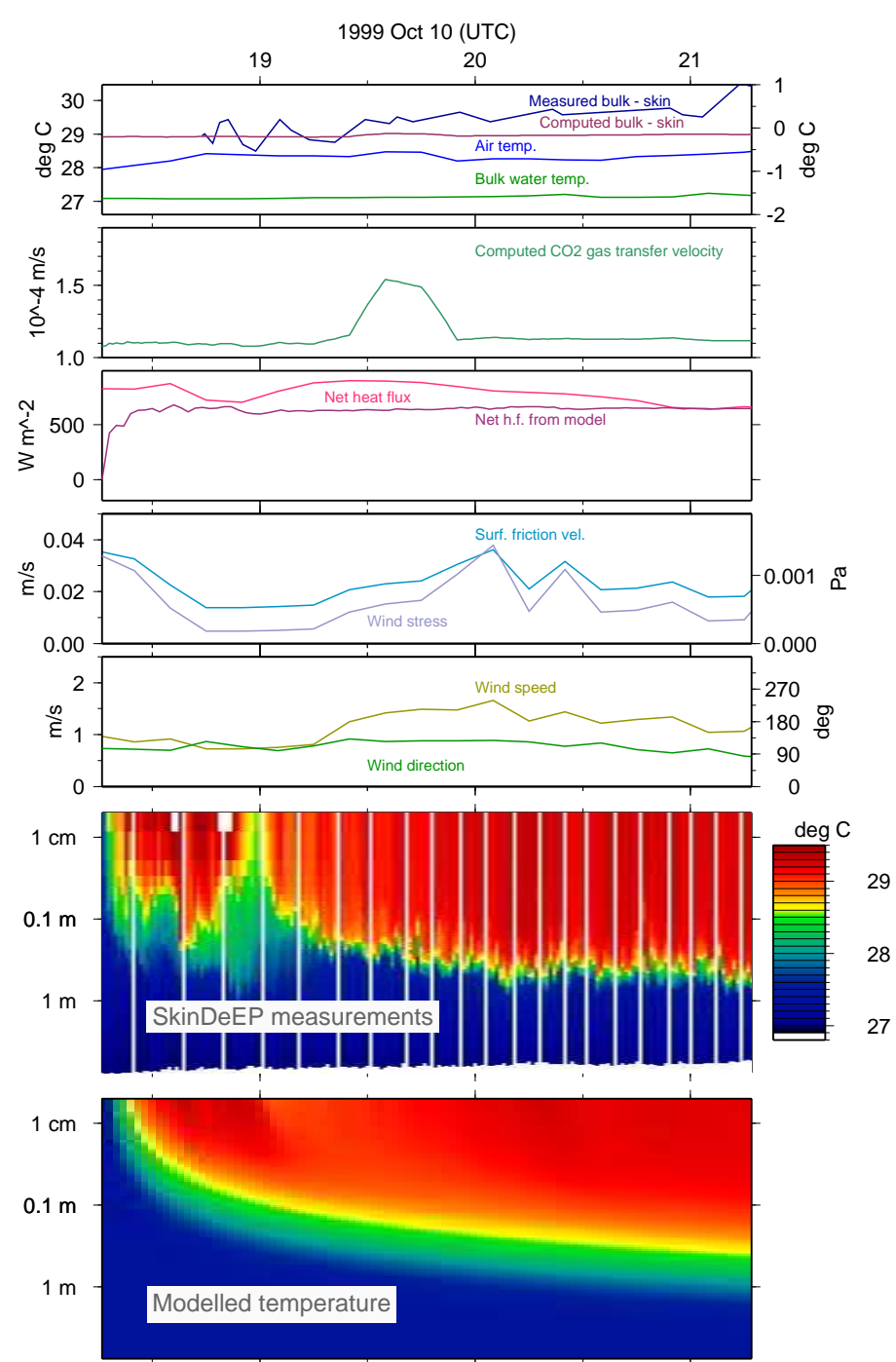

1920

21

1999 Oct 10 (UTC)

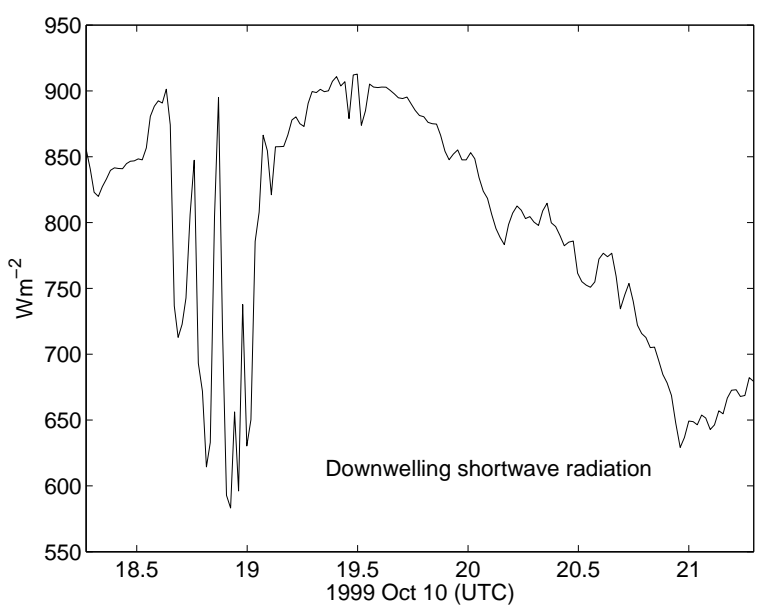

Fig. 4. Observations and model results from Station T/S Irwin, 1999 October 10, including details of the downwelling shortwave radiation (bottom frame). The modelled net heat flux is obtained from Eq. 6. The modelled bulk-skin temperature difference and $\mathrm{CO}_{2}$ flux are computed from the observed meteorological parameters from the ship (wind speed, air temperature, humidity, heat fluxes, precipitation) and uppermost water temperature measured by SkinDeEP, using the MOBLAM model of P. Schlüssel and A. V. Soloviev. 


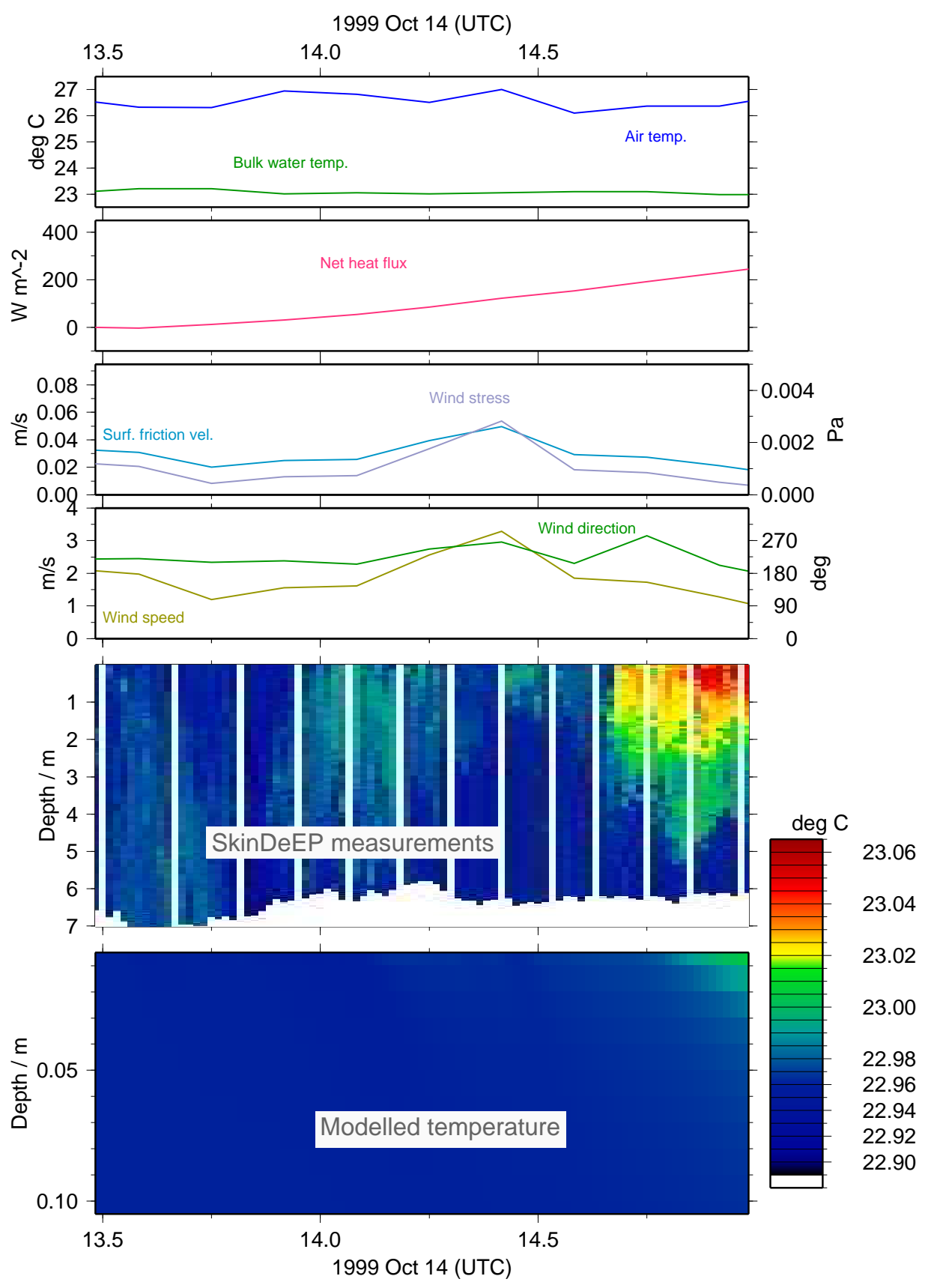

Fig. 5. Observations and model results from Station Isla San Esteban 2, 1999 October 14

0.4 , is underpredicting the amount of vertical mixing. In such a case, further investigations are required to determine how the model parameters may be tuned.

1999 October 10:

Here the modelled increase in the warm surface layer depth during the ob- 
servation period is quite similar to that actually observed. The drop in the observed surface temperature at 19:00 may be associated with the decrease in net heat flux in the previous 15 minutes, but the associated changes in the depth of the warm surface layer are not reproduced in the model. The greater wind speed in the period around 20:00, together with the positive air-sea temperature difference, tend to increase the temperature in the upper few centimetres of the ocean, and this is reproduced in both measurements and model results. Again, the agreement between model results and measurements is good, considering the fact that the model does not take stratification into account.

The sudden cooling in the water surface at about 19:00 on October 10 coincided with the passage of a cloud, which is visible in the downwelling shortwave data (bottom frame of Figure 4). This had a dramatic and immediate effect on the surface warming, presumably because of the absence of wind mixing.

\section{October 14:}

In this case the model appears to make a poor prediction of the temperature evolution of the surface layer of the ocean, when compared with the measurements. However, the temperature in the water column is rather uniform, varying by less than $0.15 \mathrm{~K}$ over the whole domain. The turbulent diffusion predicted by the model suppresses any developing non-uniformity in the temperature profile, an effect which would be mitigated if stratification were taken into account.

\section{Additional measurements and model results}

For the October 10 data set, a number of additional measurements and model results are presented. The downward heat flux $Q_{m}(t)$ through the surface computed from the present model is given by:

$$
Q_{m}(t)=\rho_{w} C \int_{0}^{t} \frac{d T\left(0^{-}, t^{\prime}\right)}{d t^{\prime}}\left[\frac{\left(u_{*}\left(t^{\prime}\right)\right)^{2}}{\lambda U\left(t^{\prime}\right)}\right] d t^{\prime}
$$

with $T\left(0^{-}, t^{\prime}\right)$ being the uppermost water temperature measured by SkinDeEP.

The bulk-skin temperature difference and gas flux are computed from the observed meteorological parameters from the ship (wind speed, air temperature, humidity, heat fluxes, precipitation) and uppermost (bulk) water temperature measured by SkinDeEP, using the Molecular Oceanic Boundary LAyer Model 
$(\text { MOBLAM })^{2}$, by Peter Schlüssel and A. V. Soloviev. The MOBLAM model is a surface renewal model, which takes account of solar and long wave radiation, turbulent and diffusive fluxes of sensible and latent heat, and impact of rain on the cool skin (Soloviev and Schlüssel 1996; Schlüssel et al. 1997; Craeye and Schlüssel 1998).

Heat flux:

The heat flux computed by the present model, after a short period of adjustment, settles down to a fairly constant level which is roughly equal to the net heat flux deduced from observations. Given the simplicity of the model and the fact that no parameter adjustment has been made, this is remarkably good agreement.

Bulk-skin temperature difference:

The bulk-skin temperature difference calculated from the MOBLAM model gives values of between $-0.2 \mathrm{~K}$ and $-0.15 \mathrm{~K}$, which are considerably smaller than the measured values using SkinDeEP and the M-AERI interferometer. This considerable discrepancy requires further investigation.

Gas flux:

The $\mathrm{CO}_{2}$ gas transfer velocity, computed by MOBLAM from the observed meteorological parameters from the ship (wind speed, air temperature, humidity, heat fluxes, precipitation) and uppermost (bulk) water temperature measured by SkinDeEP, is fairly constant, except for enhanced values between 19:20 and 20:00. The increasing values are associated by an increase in wind stress, which will increase the amount of turbulent diffusion, whereas the decreasing values are associated with an increase in the sea surface temperature and consequent decrease in $\mathrm{CO}_{2}$ solubility.

Daytime-night-time differences:

Shipboard logistics dictated that SkinDeEP was deployed during the afternoon. The one exception was on October 14, but the data set was too limited to provide any conclusive evidence for daytime-night-time differences.

${ }^{2}$ MOBLAM is available on the Internet from http://www.nova.edu/ocean/ gasex/Moblam8.f90, the version used here being from 1999 February 10. The model is described on http://www.nova.edu/ocean/gasex/micro.html. 


\section{Discussion and conclusion}

The time-dependent model presented in this paper is designed to provide an economical method of computing the evolution of the current (momentum), temperature, heat and mass flux in the near-surface layer of the ocean. Although it does not take account of stratification or of the Earth's rotation, nevertheless, given the simplicity of the model and the fact that no tuning was performed on the model parameters, it is shown to provide useful results for the time evolution of the temperature distribution in the oceanic surface layer over the measurement periods of the order of 2 hours. Some of the discrepancies we found may be explained as the result of horizontal advection, and by the model not taking account of the effect of stratification. It may also be the case that the amount of vertical mixing is underestimated, as indicated to a certain extent by the observations of Figure 3, and by the low von Kármán 'constant' of the model, discussed in section 2.4. It should be noted, however, that the turbulent flow and mixing in the near-surface boundary layer of the ocean need not be represented by the 'classical' von Kármán 'constant' value of 0.4 , as the physical conditions are by no means the same as those in a classical turbulent wall layer. A resolution of the problem of turbulent mixing intensity may be obtainable in the future by conducting an analysis of further, more detailed time-dependent coupled observations of velocity, temperature, and turbulence in the near-surface atmospheric and oceanic boundary layers.

The computed net surface heat flux values are largely consistent with observed values. A suitable application for the model would be as an interface between complex time-independent models for interfacial flux of momentum, heat, and mass, and time-dependent three-dimensional numerical models of ocean circulation which employ turbulence closure schemes and account for stratification and the Coriolis force.

The flux of $\mathrm{CO}_{2}$ and other gas species through the sea surface can be computed using MOBLAM or similar time-independent surface models. A straightforward extension of the present time-dependent model should be capable of extending these flux predictions and computing the concentration and flux of $\mathrm{CO}_{2}$ further into the water column.

It should be possible to test the present model against time-dependent models with one (vertical) spatial dimension, such as the warm layer model of Price et al. (1986), and with models which predict bulk fluxes such as the TOGACOARE algorithm (Fairall et al. 1996a,b) ${ }^{3}$. Such a study, including the use of turbulent closure models for stratified flows, and a more detailed evaluation of the effect of horizontal advection, would be a suitable topic for a future

\footnotetext{
3 The algorithm is currently available on the Internet at URL http://www . coaps . fsu.edu/COARE/flux_algor/flux.html
} 
paper.

Acknowledgements

The work was funded by Research Council of Norway projects 127872/720 and $155923 / 700$, by the Norwegian high performance computing consortium under grant NN2932K, and by European Commission Contract No. ERBFMBICT983162. Additional funding was provided by NSF grant OCE-0326814. Observational data are from the Marine Optical Characterisation Experiment (MOCE-5), conducted by the U.S. National Aeronautic and Space Administration and National Oceanic and Atmospheric Administration. The computer code MOBLAM was made available on the Internet at address http://www.nova.edu/ocean/gasex/Moblam8.f90 by Dr. Peter Schlüssel. The authors would like to thank Walter Eifler, Hans Burchard, and one anonymous referee for constructive criticism of the manuscript. This is Publication No. A 84 from the Bjerknes Centre for Climate Research, and Woods Hole Oceanographic Institution Contribution No. 11347.

\section{References}

T. Audunson. Fate of oil spills on the Norwegian continental shelf. In Proc. 1979 Oil Spill Conf., Washington, D.C., 1979. American Petroleum Institute. API Publ. No. 4308.

M. L. Banner, A. V. Babanin, and I. R. Young. Breaking probability for dominant waves on the sea surface. J. Phys. Oceanogr., 30(12):3145-3160, 2000 .

M. L. Banner and O. M. Phillips. On the incipient breaking of small scale waves. J. Fluid Mech., 65(4):647-656, 1974.

H. Burchard. Applied Turbulence Modelling in Marine Waters. Springer, Berlin, 2002, 229 pp.

H. Burchard, O. Petersen, and T. P. Rippeth. Comparing the performance of the Mellor-Yamada and the $k-\epsilon$ two-equation turbulence models. $J$. Geophys Res., 103(C5):10543-10554, 1998.

C. Craeye and P. Schlüssel. Rainfall on the sea: Surface renewal and wave damping. Bound.-Layer Meteorol., 89:349-355, 1998.

M. A. Donelan, J. Hamilton, and W. H. Hui. Directional spectra of windgenerated waves. Phil. Trans. R. Soc. Lond., Ser. A, 315:509-562, 1985.

C. J. Donlon, P. J. Minnett, C. Gentemann, T. J. Nightingale, I. J. Barton, B. Ward, and J. Murray. Towards improved validation of satellite sea surface skin temperature measurements for climate research. J. Clim., 15:353-369, 2002 . 
W. Eifler. Modelling the skin-bulk temperature difference near the seaatmosphere interface for remote sensing applications. In Proc. Conf. 'Space in the Service of a Changing Earth', Munich, 30 March-4 April 1992, pp. 335-341.

W. Eifler. A hypothesis on momentum and heat transfer near the seaatmosphere interface and a related simple model. J. Mar. Sys., 64:133-153, 1993.

V. W. Ekman. On the influence of the Earth's rotation on ocean-currents. Ark. Mat. Astr. Fys., 2(11):1-52, 1905.

C. W. Fairall, E. F. Bradley, J. S. Godfrey, G. A. Wick, J. B. Edson, and G. S. Young. Cool-skin and warm-layer effects on sea surface temperature. J. Geophys Res., 101:1295-1308, 1996a.

C. W. Fairall, E. F. Bradley, D. P. Rogers, J. B. Edson, and G. S. Young. Bulk parameterization of air-sea fluxes for TOGA COARE. J. Geophys Res., 101: 3747-3764, 1996b.

C. W. Fairall, J. E. Hare, J. B. Edson, and W. McGillis. Parameterization and micrometeorological measurement of air-sea gas transfer. Bound.-Layer Meteorol., 96:63-105, 2000.

J. C. Huang. A review of the state-of-the-art oil spill fate/behavior models. Proc. 1983 Oil Spill Conf., San Antonio, Texas, pp. 313-322. American Petroleum Institute, 1983.

N. E. Huang. On surface drift currents in the ocean. J. Fluid Mech., 91: 191-208, 1979.

P. A. E. M. Janssen. Wave-induced stress and the drag of air flow over sea waves. J. Phys. Oceanogr., 19:745-754, 1989.

A. D. Jenkins. Comparison of current measurements over the Norwegian continental shelf, using near-surface moored current meters and surface drifters. Proc. Conf. 'Current Measurements Offshore', London, 17 May 1984. Soc. Underwater Technol., 1984

A. D. Jenkins. Wind and wave induced currents in a rotating sea with depthvarying eddy viscosity. J. Phys. Oceanogr., 17:938-951, 1987a.

A. D. Jenkins. A Lagrangian model for wind and wave induced near-surface currents. Coastal Engng, 11:513-526, 1987b.

A. D. Jenkins. The use of a wave prediction model for driving a near-surface current model. Dt. Hydrogr. Z., 42:133-149, 1989.

A. D. Jenkins. Do strong winds blow waves flat? In B. L. Edge and J. M. Hemsley, editors, Ocean Wave Measurement and Analysis, Proc. Conf. 'WAVES 2001', San Francisco, volume 1, pp. 494-500. Amer. Soc. Civ. Engrs, 2001.

A. D. Jenkins, R. B. Olsen, and S. Christianidis. Intercomparison trials: nearsurface current measurements over the Norwegian continental shelf. Proc. IEEE 3rd Working Conf. on Current Measurement, Airlie, Virginia, January 1986. IEEE, New York, pp. 20-25.

A. D. Jenkins and B. Ward. Time-dependent modelling of the temperature profile near the sea surface. Report from the Research Council of Norway project 'Measurement and modelling of controlling factors for air-sea fluxes', 
Nansen Environmental and Remote Sensing Center, Bergen, Norway, 2003. A. T. Jessup, C. J. Zappa, V. Hesany, M. R. Loewen, and M. G. Skafel. Dependence of the skin layer recovery rate on heat flux and temperature. In B. Jähne and E. C. Monahan, editors, Selected Papers from the Third International Symposium on Air-Water Gas Transfer, July 24-27, 1995, Heidelberg University, pp. 601-610, Hanau, Germany, 1995. AEON Verlag \& Studio.

C. L. McNeil and L. Merlivat. The warm oceanic surface layer: Implications for $\mathrm{CO}_{2}$ fluxes and surface gas measurements. Geophys. Res. Letts, 23: 3575-3578, 1996.

O. S. Madsen. A realistic model of the wind-induced Ekman boundary layer. J. Phys. Oceanogr., 7:248-255, 1977.

P. J. Minnett, R. O. Knuteson, F. A. Best, B. J. Osborne, J. A. Hanafin, and O. B. Brown. The Marine-Atmospheric Emitted Radiance Interferometer (M-AERI), a high-accuracy, sea-going infrared spectroradiometer. J. Atmos. Ocean. Technol., 18:994-1013, 2001.

P. J. Minnett and B. Ward. Measurement of near-surface ocean temperature variability - consequences on the validation of AATSR on ENVISAT, 2000. Proc. ERS-ENVISAT Sympos., Gothenburg, Sweden, ESA SP-461.

A. S. Monin and A. M. Obukhov. Basic laws of turbulent mixing in the ground layer of the atmosphere. Trudy Geofiz. Inst. Akad. Nauk SSSR, 24(151):163-187, 1954.

R. Nagaosa. Direct numerical simulation of vortex structures and turbulent scalar transfer across a free surface in a fully developed turbulence. Phys. Fluids, 11(6):1581-1595, 1999.

J. F. Price, R. A. Weller, and R. Pinkel. Diurnal cycling: Observations and models of the upper ocean response to diurnal heating, cooling, and wind mixing. J. Geophys Res., 91:8411-8427, 1986.

P. Schlüssel, W. J. Emery, H. Grassl, and T. Mammen. On the bulk skin temperature difference and its impact on satellite remote sensing of sea surface temperature. J. Geophys Res., 95:13 341-13 356, 1990.

P. Schlüssel, A. V. Soloviev, and W. J. Emery. Cool and freshwater skin of the ocean during rainfall. Bound.-Layer Meteorol., 82:437-472, 1997.

E. D. Skyllingstad and D. W. Denbo. An ocean large-eddy simulation of Langmuir circulations and convection in the surface mixed layer. J. Geophys. Res., 100(C5):8501-8522, 1995.

K. C. Soetje and K. Huber. A compilation of data on the thermal stratification at the central station in the northern North Sea during FLEX '76. 'Meteor'Forsch.-Ergebnisse, Reihe A, 22:69-70, 1980.

A. V. Soloviev and P. Schlüssel. Parameterization of the cool skin of the ocean and of the air-ocean gas transfer on the basis of modelling surface renewal. J. Phys. Oceanogr., 24:1339, 1994.

A. V. Soloviev and P. Schlüssel. Evolution of cool skin and direct air-sea gas transfer coefficient during daytime. Bound.-Layer Meteorol., 77:45-68, 1996. 
R. B. Stull. Review of non-local mixing in turbulent atmospheres: Transilient turbulence theory. Bound.-Layer Meteorol., 62:21-96, 1993.

S. A. Thorpe. On the determination of $K_{V}$ in the near-surface ocean from acoustic measurements of bubbles. J. Phys. Oceanogr., 14:855-863, 1984.

B. Ward and P. J. Minnett. An autonomous profiler for near surface temperature measurements. In M. A. Donelan et al., editors, Gas Transfer at Water Surfaces. American Geophysical Union, Washington, D.C., 2002.

B. Ward and S. Redfern. A neural network model for predicting the bulk-skin temperature difference at the sea surface. Int. J. Rem. Sens., 20:3533-3548, 1999.

B. Ward, R. Wanninkhof, W. R. McGillis, A. T. Jessup, M. D. DeGrandpre, J. E. Hare, and J. B. Edson. Biases in the air-sea flux of $\mathrm{CO}_{2}$ resulting from ocean surface temperature gradients. J. Geophys. Res., 109:C08S08, doi:10.1029/2003JC001800, 2004a.

B. Ward, R. Wanninkhof, P. J. Minnett, and M. Head. SkinDeEP: A profiling instrument for upper decameter sea surface measurements. J. Atmos. Ocean Technol., 21:207-222, 2004b.

B. Ward and P. J. Minnett. Measurements of near surface temperature $J$. Geophys. Res. (submitted), 2004.

J. E. Weber. Steady wind- and wave-induced currents in the open ocean. J. Phys. Oceanogr., 13:524-530, 1983.

J. Wu. Wind-stress coefficients over sea-surface from breeze to hurricane. J. Geophys. Res., 87(C12):9704-9706, 1982. 